\title{
Four-year follow-up of the randomised comparison between an everolimus-eluting bioresorbable scaffold and an everolimus-eluting metallic stent for the treatment of coronary artery stenosis (ABSORB II Trial)
}

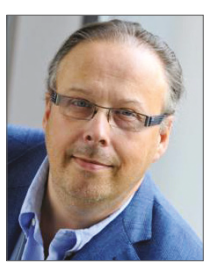

Bernard Chevalier ${ }^{1 *}$, MD; Angel Cequier², MD; Dariusz Dudek ${ }^{3}, \mathrm{MD}$; Michael Haude ${ }^{4}$, MD; Didier Carrie ${ }^{5}, \mathrm{MD}, \mathrm{PhD}$; Manel Sabaté ${ }^{6}, \mathrm{MD}, \mathrm{PhD}$; Stephan Windecker ${ }^{7}, \mathrm{MD}, \mathrm{PhD}$; Sebastian Reith ${ }^{8}, \mathrm{MD}$; Manuel de Sousa Almeida ${ }^{9}, \mathrm{MD}, \mathrm{PhD}$; Gianluca Campo ${ }^{10}$, MD; Andres Iñiguez ${ }^{11}$, MD; Yoshi Onuma ${ }^{12}, \mathrm{MD}, \mathrm{PhD}$; Patrick W. Serruys ${ }^{13}, \mathrm{MD}, \mathrm{PhD}$

1. Ramsay Générale de Santé, Institut Cardiovasculaire Paris Sud, Massy, France; 2. Bellvitge University Hospital, Barcelona, Spain; 3. Department of Cardiology and Cardiovascular Interventions, Institute of Cardiology, Jagiellonian University, Krakow, Poland; 4. Städtisches Kliniken Neuss, Lukaskrankenhaus GmbH, Neuss, Germany; 5. Department of Cardiology, CHU Rangueil, Toulouse, France; 6. Cardiovascular Institute, Hospital Clinic, University of Barcelona, Institut d'Investigacions Biomèdiques August Pi i Sunyer (IDIBAPS), Barcelona, Spain; 7. Department of Cardiology, Bern University Hospital, Bern, Switzerland; 8. Department of Internal Medicine I, University Hospital of the RWTH Aachen, Aachen, Germany; 9. Department of Cardiology, Centro Hospital de Lisboa Ocidental, Lisbon, Portugal; 10. Cardiology Unit, Azienda Ospedaliera Universitaria di Ferrara, Cone (FE), Italy and Maria Cecilia Hospital, GVM Care \& Research, Cotignola (RA), Italy; 11. Hospital Alvaro Cunqueiro, Vigo, Spain; 12. Thoraxcenter, Erasmus Medical Center, Rotterdam, the Netherlands; 13. NHLI, Imperial College London, London, United Kingdom

GUEST EDITOR: Alec Vahanian, MD, PhD; Department of Cardiology, Hôpital Bichat, Paris, France and University Paris VII, Paris, France

\section{Introduction}

Transient scaffolding using bioresorbable drug-eluting polymeric platforms aims to improve late clinical outcomes through restoration of vasomotion, adaptive shear stress, late plaque regression and expansive remodelling. However, long-term data are scarce. Several studies have reported the midterm comparison of the Absorb $^{\text {TM }}$ bioresorbable scaffold (Abbott Vascular, Santa Clara, CA, USA) with its metallic stent counterpart, XIENCE ${ }^{\circledR}$ (Abbott Vascular $)^{1,2}$. Preclinical evaluation has shown that scaffold degradation is complete by 36 months $^{3}$. The aim of this report is to present the first four-year comparative evaluation after the expected full resorption of the scaffold device.

\section{Editorial, see page 1506}

\section{Methods}

The trial design and methods, as well as the study population, were described in previous reports ${ }^{4,5}$. An amendment was appended to the initial trial design to extend the clinical follow-up beyond the three-year primary endpoint timeline up to five years; twenty patients refused to re-consent to this extended follow-up (nine in the Absorb arm and 11 in the XIENCE arm). A single four-year follow-up visit was performed in $86 \%$ (Absorb) and 84\% (XIENCE) of the initial cohorts. Reasons for missing evaluation are described in the flow chart (Figure 1). All clinical events were adjudicated by an independent clinical events committee. Fisher's exact test was used to compare binary variables of clinical outcome. For time-to-event variables, survival curves were constructed using Kaplan-Meier estimates and the log-rank test was used.

\section{Results}

The endpoints of the three-year angiographic follow-up were reported in a previously published 3-year clinical comparative study $^{1}$. Between three and four years, target lesion failure (or the device-oriented composite endpoint [DOCE]) increased from

*Corresponding author: Ramsay Générale de Santé, Institut Cardiovasculaire Paris Sud, 6 Avenue du Noyer Lambert, 91300

Massy, France.E-mail: bchevali@aol.com 


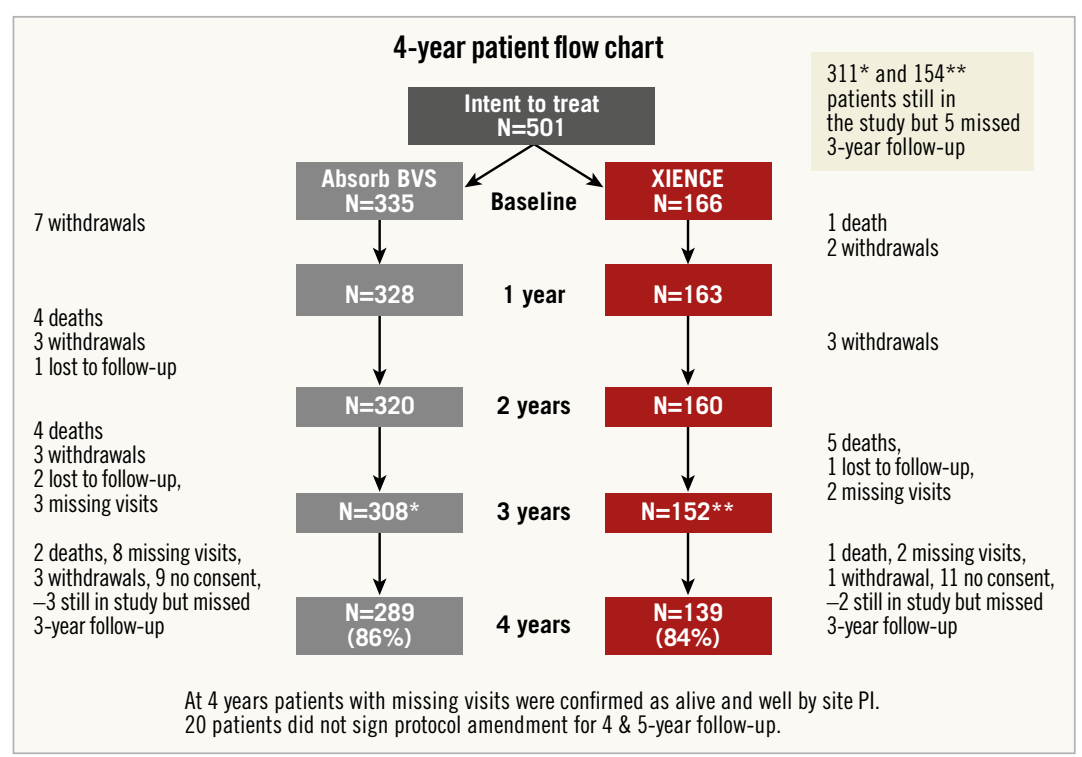

Figure 1. Study flow chart. *Absorb BVS group; **XIENCE group; PI: principal investigator

$10.5 \%$ to $11.5 \%$ in the Absorb arm and from $5.0 \%$ to $6.0 \%$ in the XIENCE arm, with $1 \%$ and $0.7 \%$ absolute difference, respectively $(\mathrm{p}=0.3)$. No statistically significant difference could be observed ( $\mathrm{p}=0.063$ ) (Figure 2). Two patients in the Absorb arm and one in the XIENCE arm died between three and four years: causes of death were one sudden death in each arm and one brain tumour in the Absorb group. The patient-oriented composite endpoint (POCE) was observed in $23.6 \%$ in the Absorb arm and $26.7 \%$ in the XIENCE arm $(p=0.47)$. The individual components of the composite endpoints and non-hierarchical analyses of the clinical events are presented in Table 1. No case of additional very late scaffold/stent thrombosis was noted in either arm between three and four years, with a four-year rate of $3.0 \%$ versus $0.0 \%(\mathrm{p}=0.035)$ (Figure 3). DAPT prescription slightly decreased from $29.8 \%$ to $25.9 \%$ in the Absorb arm and from $27.7 \%$ to $21.1 \%$ in the XIENCE arm, with no significant difference between the two arms.

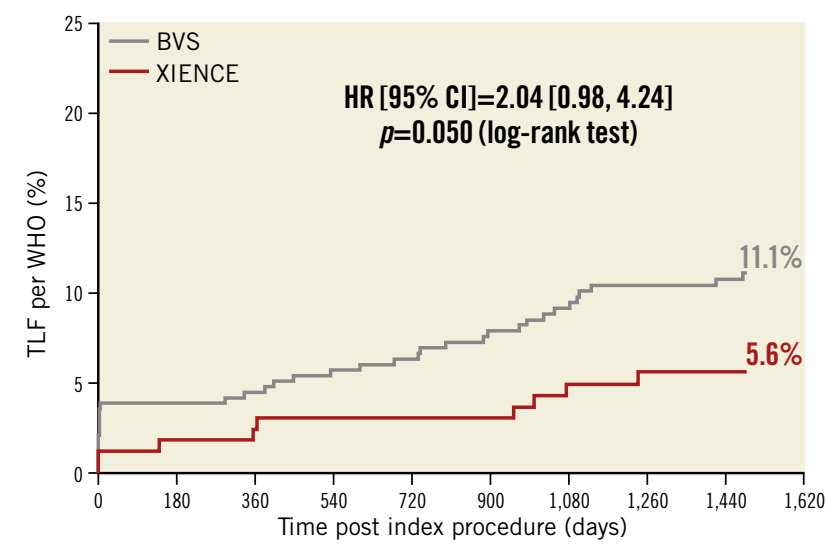

Figure 2. Target lesion failure up to four years.

\section{Discussion}

This first description of the four-year follow-up of a randomised comparison between Absorb and XIENCE showed a similarly low rate of additional target lesion failure (TLF) events in both groups after three years without additional instances of scaffold thrombosis despite the absence of DAPT in three quarters of the cohort. Very late scaffold thrombosis during the third year was the main contributor to the significant difference in TLF rates at three years.

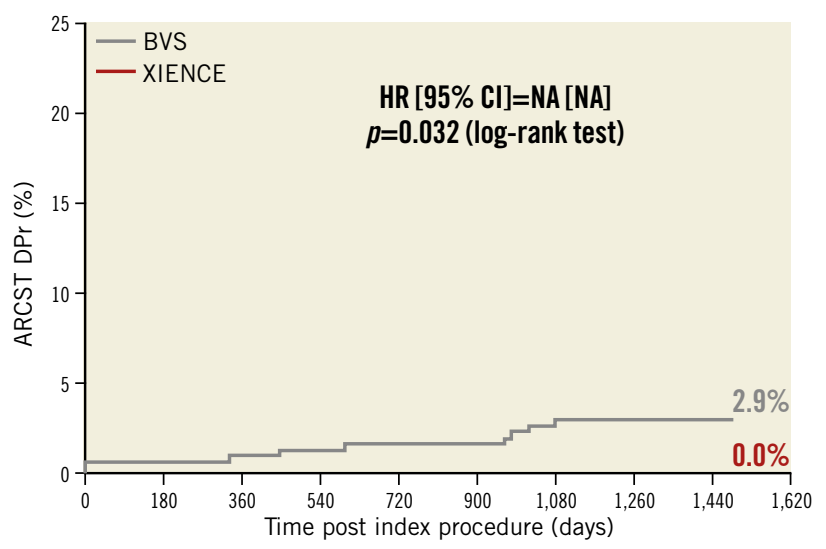

Figure 3. Stent thrombosis up to four years. ARCST DPr: Stent thrombosis adjudicated as definite/probable according to the Academic Research Consortium definitions

A downturn of events has now been observed between three and four years, impacting positively on the TLF difference at four years. Intraluminal dismantling or late discontinuities of the scaffold have been proposed as possible mechanisms of this peak of thrombosis between 32 and 36 months after implantation as described in case reports $^{6}$ and in the ABSORB Japan trial ${ }^{7}$. A similar downturn was observed in terms of the POCE after a peak of events at 36 months 
Table 1. Outcomes at 4 years.

Clinical outcomes - non-hierarchical events at 4 years

\begin{tabular}{|c|c|c|c|}
\hline & $\begin{array}{c}\text { Absorb BVS } \\
\mathbf{N = 3 3 5}\end{array}$ & $\begin{array}{c}\text { XIENCE } \\
\mathbf{N = 1 6 6}\end{array}$ & $\boldsymbol{p}$-value \\
\hline Death* (\%) & 3.2 & 4.7 & 0.4268 \\
\hline Cardiac & 1.3 & 2.7 & 0.2795 \\
\hline Vascular & 0.3 & 0.0 & 1.0000 \\
\hline Non-cardiovascular & 1.6 & 2.0 & 0.7173 \\
\hline Myocardial infarction (\%) & 8.6 & 3.3 & 0.0363 \\
\hline Q-wave & 3.2 & 1.3 & 0.3528 \\
\hline Non-Q-wave & 5.7 & 2.0 & 0.0704 \\
\hline
\end{tabular}

Revascularisations - non-hierarchical events at 4 years

\begin{tabular}{|l|r|r|r|}
\hline All revascularisation* (\%) & 17.5 & 22.7 & 0.1875 \\
\hline All TLR & 8.3 & 5.3 & 0.2545 \\
\hline ID-TLR & 6.7 & 2.0 & 0.0330 \\
\hline All NTL-TVR & 4.8 & 9.3 & 0.0579 \\
\hline All NTVR & 8.9 & 13.3 & 0.1440 \\
\hline
\end{tabular}

Clinical outcomes - non-hierarchical events at 3-4 years

\begin{tabular}{|l|r|r|l|}
\hline Death*, $\mathrm{n}(\%)$ & $2(0.7)$ & $1(0.7)$ & 1.0000 \\
\hline Cardiac & $1(0.3)$ & $1(0.7)$ & 0.5408 \\
\hline Vascular & $0(0.0)$ & $0(0.0)$ & 1.0000 \\
\hline Non-cardiovascular & $1(0.3)$ & $0(0.0)$ & 1.0000 \\
\hline Myocardial infarction, $\mathrm{n}(\%)$ & $1(0.3)$ & $0(0.0)$ & 1.0000 \\
\hline Q-wave & $0(0.0)$ & $0(0.0)$ & 1.0000 \\
\hline Non-Q-wave & $1(0.3)$ & $0(0.0)$ & 1.0000 \\
\hline All revascularisation*, $\mathrm{n}(\%)$ & $10(3.3)$ & $1(0.7)$ & 0.1142 \\
\hline All TLR & $2(0.7)$ & $0(0.0)$ & 1.0000 \\
\hline All NTL-TVR & $4(1.3)$ & $0(0.0)$ & 0.3102 \\
\hline All NTVR & $6(2.0)$ & $1(0.7)$ & 0.4373 \\
\hline
\end{tabular}

\section{Scaffold/stent thrombosis at 4 years}

\begin{tabular}{|l|l|l|c|}
\hline Definite ST* 0-1,488 days (\%) & 2.6 & 0.0 & 0.0583 \\
\hline Acute/subacute (0-30 days) & 0.6 & 0.0 & 1.0000 \\
\hline Late (31-365 days) & 0.0 & 0.0 & 1.0000 \\
\hline Very late (365-1,488 days) & 1.8 & 0.0 & 0.1851 \\
\hline $\begin{array}{l}\text { Very late between 3 and } \\
\text { 4-year follow-up ( } \mathrm{n})\end{array}$ & 0 & 0 & $\mathrm{NA}$ \\
\hline $\begin{array}{l}\text { Definite/probable ST* 0-1,488 } \\
\text { days (\%) }\end{array}$ & 3.0 & 0.0 & 0.0347 \\
\hline $\begin{array}{l}\text { Acute/subacute (0-30 days) } \\
\text { Late (31-365 days) }\end{array}$ & 0.6 & 0.0 & 1.000 \\
\hline $\begin{array}{l}\text { Very late (365-1,488 days) } \\
\text { Very late between 3 and } \\
\text { 4-year follow-up ( } \mathrm{n} \text { ) }\end{array}$ & 0.3 & 0.0 & 1.0000 \\
\hline
\end{tabular}

Post-procedure usage of antiplatelet medication up to 4 years

\begin{tabular}{|l|l|l|l|l|}
\hline \multirow{3}{*}{ On aspirin (\%) } & At 1 year & 95.8 & 95.2 & 0.7473 \\
\cline { 2 - 5 } & At 4 years & 84.4 & 81.3 & 0.3794 \\
\hline \multirow{3}{*}{ On DAPT (\%) } & At 1 year & 81.0 & 80.7 & 0.9357 \\
\cline { 2 - 5 } & At 2 years & 28.6 & 28.9 & 0.9442 \\
\cline { 2 - 5 } & At 3 years & 29.8 & 27.7 & 0.6254 \\
\cline { 2 - 5 } & At 4 years & 25.9 & 21.1 & 0.2372 \\
\hline
\end{tabular}

which is likely to be related to systematic angiographic follow-up inducing non-TLR revascularisations. Scaffold sizing and implantation technique have a key impact on three-year clinical results, as shown in a recent meta-analysis and a report by Serruys et $\mathrm{al}^{8,9}$. The impact of these factors, as well as DAPT prolongation, on longerterm outcomes is still unknown and needs to be demonstrated.

\section{Limitations}

Further long-term follow-up data from larger studies are necessary to overcome the two main limitations of the ABSORB II study: 1) the trial was not powered to evaluate clinical endpoints; 2) the implantation technique reflects the state of the art at the time of enrolment in 2011-2012 and did not take into account the more recent findings on bioresorbable scaffold usage in terms of size selection, lesion preparation and deployment technique.

\section{Conclusion}

A downturn of events was observed beyond the expected resorption time. Further long-term evaluation in larger randomised studies is necessary to confirm this observation.

\section{Impact on daily practice}

Previous midterm follow-up reports after Absorb implantation have shown an increase of scaffold thrombosis leading to an excess of target lesion failure. The four-year follow-up of the ABSORB II Trial is the first observation of clinical outcome after the expected resorption time in the setting of a randomised clinical trial. No additional thrombosis was observed between three and four years. The implications for long-term routine follow-up and dual antiplatelet therapy duration may need additional information from larger trials and meta-analysis of ABSORB studies.

\section{Guest Editor}

This paper was guest edited by Alec Vahanian, $\mathrm{MD}, \mathrm{PhD}$; Department of Cardiology, Hôpital Bichat, Paris, and University Paris VII, Paris, France.

\section{Funding}

The ABSORB II Trial (NCT01425281) was funded by Abbott Vascular, Santa Clara, CA, USA.

\section{Conflict of interest statement}

P. Serruys is a member of the Advisory Board of Abbott Vascular. B. Chevalier was a consultant for Abbott Vascular. Y. Onuma is a member of the Advisory Board for Abbott Vascular and has received speaker honoraria from Terumo. M. Sabate is a consultant for Abbott Vascular. D. Dudek is a member of the Advisory Board and receives research and education support from Abbott. The other authors have no conflicts of interest to declare. The Guest Editor declares receiving consultancy fees from Edwards Lifesciences. 


\section{References}

1. Serruys PW, Chevalier B, Sotomi Y, Cequier A, Carrié D, Piek JJ, Van Boven AJ, Dominici M, Dudek D, McClean D, Helqvist S, Haude M, Reith S, de Sousa Almeida M, Campo G, Iñiguez A, Sabaté M, Windecker S, Onuma Y. Comparison of an everolimus-eluting bioresorbable scaffold with an everolimus-eluting metallic stent for the treatment of coronary artery stenosis (ABSORB II): a 3 year, randomised, controlled, single-blind, multicentre clinical trial. Lancet. 2016;388:2479-91.

2. Ali ZA, Serruys PW, Kimura T, Gao R, Ellis SG, Kereiakes DJ, Onuma Y, Simonton C, Zhang Z, Stone GW. 2-year outcomes with the Absorb bioresorbable scaffold for treatment of coronary artery disease: a systematic review and meta-analysis of seven randomised trials with an individual patient data substudy. Lancet. 2017;390:760-72.

3. Otsuka F, Pacheco E, Perkins LE, Lane JP, Wang Q, Kamberi M, Frie M, Wang J, Sakakura K, Yahagi K, Ladich E, Rapoza RJ, Kolodgie FD, Virmani R. Long-term safety of an everolimus-eluting bioresorbable vascular scaffold and the cobaltchromium XIENCE V stent in a porcine coronary artery model. Circ Cardiovasc Interv. 2014;7:330-42.

4. Diletti R, Serruys PW, Farooq V, Sudhir K, Dorange C, Miquel-Hebert K, Veldhof S, Rapoza R, Onuma Y, GarciaGarcia HM, Chevalier B. ABSORB II randomized controlled trial: a clinical evaluation to compare the safety, efficacy, and performance of the Absorb everolimus-eluting bioresorbable vascular scaffold system against the XIENCE everolimus-eluting coronary stent system in the treatment of subjects with ischemic heart disease caused by de novo native coronary artery lesions: rationale and study design. Am Heart J. 2012;164:654-63.

5. Serruys PW, Chevalier B, Dudek D, Cequier A, Carrié D, Iniguez A, Dominici M, van der Schaaf RJ, Haude M, Wasungu L,
Veldhof S, Peng L, Staehr P, Grundeken MJ, Ishibashi Y, GarciaGarcia HM, Onuma Y. A bioresorbable everolimus-eluting scaffold versus a metallic everolimus-eluting stent for ischaemic heart disease caused by de-novo native coronary artery lesions (ABSORB II): an interim 1-year analysis of clinical and procedural secondary outcomes from a randomised controlled trial. Lancet. 2015;385:43-54.

6. Räber L, Brugaletta S, Yamaji K, O’Sullivan CJ, Otsuki S, Koppara T, Taniwaki M, Onuma Y, Freixa X, Eberli FR, Serruys PW, Joner M, Sabaté M, Windecker S. Very Late Scaffold Thrombosis: Intracoronary Imaging and Histopathological and Spectroscopic Findings. J Am Coll Cardiol. 2015;66: 1901-14.

7. Onuma Y, Sotomi Y, Shiomi H, Ozaki Y, Namiki A, Yasuda S, Ueno T, Ando K, Furuya J, Igarashi K, Kozuma K, Tanabe K, Kusano H, Rapoza R, Popma JJ, Stone GW, Simonton C, Serruys PW, Kimura T. Two-year clinical, angiographic, and serial optical coherence tomographic follow-up after implantation of an everolimus-eluting bioresorbable scaffold and an everolimus-eluting metallic stent: insights from the randomised ABSORB Japan trial. EuroIntervention. 2016;12:1090-101.

8. Stone GW, Abizaid A, Onuma Y, Seth A, Gao R, Ormiston J, Kimura T, Chevalier B, Ben-Yehuda O, Dressler O, McAndrew T, Ellis SG, Kereiakes DJ, Serruys PW. Effect of Technique on Outcomes Following Bioresorbable Vascular Scaffold Implantation: Analysis From the ABSORB Trials. J Am Coll Cardiol. 2017; 70:2863-74

9. Serruys PW, Onuma Y. Dmax for sizing, PSP-1, PSP-2, PSP-3 or OCT guidance: interventionalist's jargon or indispensable implantation techniques for short- and long-term outcomes of Absorb BRS? EuroIntervention. 2017;12:2047-56. 